\title{
Bioequivalence Study of Two Oral Formulations of Memantine Tablets in Healthy Brazilian Volunteers after a Single Dose Administration
}

Isabela Costa César ${ }^{1,2 *}$, Ricardo Martins Duarte Byrro², Fabiana Fernandes de Santana e Silva1, Iram Moreira Mundim¹, Leonardo de Souza Teixeira ${ }^{1}$, Fernanda Crunivel de Abreu ${ }^{1}$ and Gerson Antônio Pianetti ${ }^{2}$

${ }^{1}$ Instituto de Ciências Farmacêuticas, Alameda Coronel Eugênio Jardim 53, 74175-100, Goiânia, GO, Brazil

${ }^{2}$ Departamento de Produtos Farmacêuticos, Faculdade de Farmácia, Universidade Federal de Minas Gerais, Av. Pres. Antônio Carlos 6627, 31270-901, Belo Horizonte, MG, Brazil

\begin{abstract}
The bioequivalence of a single dose of memantine $\left(\right.$ Clomenac $\left.^{\circledR}\right) 10 \mathrm{mg}$ tablets manufactured by Cobalt Pharmaceuticals, Canada/Arrow Farmacêutica Ltda was compared with a reference memantine $10 \mathrm{mg}$ tablets (Ebix ${ }^{\circledR}$, Lundbeck Inc). The single-dose, randomized-sequence, open-label, two period crossover study was conducted on a total of 26 Brazilian healthy volunteers of both genders. Nineteen blood samples were taken during $72 \mathrm{~h}$. Samples were frozen and kept until time of analysis. Plasma concentrations of memantine were determined using a validated UPLC-MS/MS method. Confidence intervals $(\mathrm{Cl}, 90 \%)$ for the peak plasma concentration $\left(\mathrm{C}_{\max }\right)$ and area under the concentration-time curve $\left(\mathrm{AUC}_{0-1}\right)$ were determined by calculating log-transformed data. The test and reference formulations were considered bioequivalent if the $90 \% \mathrm{Cls}$ for the geometric mean test/reference ratios were within a predetermined range of $80 \%$ to $125 \%$. The $90 \% \mathrm{Cl}$ for the geometric mean ratios for $\mathrm{C}_{\max }$ was $100.1 \%(92.9$ $107.9 \%$ ) and for $\mathrm{AUC}_{0-\mathrm{t}}$ was $98.8 \%$ (93.9-103.9\%). In conclusion, the tested $10 \mathrm{mg}$ memantine tablets (Clomenac ${ }^{\circledR}$ Arrow Farmacêutica Ltda.) was bioequivalent to Ebix ${ }^{\circledR} 10 \mathrm{mg}$ tablets, according to the rate and extent of absorption.
\end{abstract}

Keywords: Memantine; Tablet formulation; UPLC-MS/MS; Bioavailability; Bioequivalence

\section{Introduction}

Alzheimer disease is a fatal progressive neurodegenerative illness and the most common form of dementia, affecting as many as 25 million people worldwide [1]. Severe memory loss, confusion, and impaired cognitive abilities characterize Alzheimer disease [2]. The treatments for the disease involve pharmacological and stimulatory therapies, such as, physical exercises, cognitive training and socialization [3].

The first medications to receive FDA approval for symptomatic treatment of patients with Alzheimer disease were the acetylcholinesterase inhibitors, such as tacrine, donepezil, galantamine and rivastigmine [1].

Memantine (Figure 1), which has a different mechanism of action, is a moderate-affinity, noncompetitive antagonist of N-methyl-Daspartate receptors, approved for the treatment of moderate to severe Alzheimer disease. In addition to its benefits on cognition function and global status, memantine treatment may also help alleviate behavioral symptoms $[4,5]$.

After oral administration, memantine is completely absorbed, with peak plasma concentrations occurring between 3 and 7 hours. Memantine is $45 \%$ bound to plasma proteins presenting a distribution volume of approximately 9-11 L/kg, which suggests an extensive distribution into tissues. Memantine is excreted predominantly in

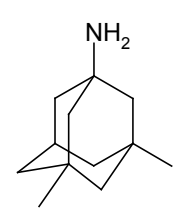

MEM

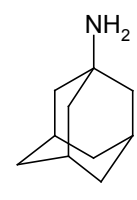

IS
Figure 1: Chemical structures of memantine (MEM) and adamantine, the internal standard (IS). urine as unchanged parent drug, in part via renal tubular secretion, and it has a terminal elimination half-life of 60 to 80 hours [6,7].

Bioequivalence studies are important to compare the systemic exposure profile of a test drug product to that of a reference product. For two orally administered drug products can be considered bioequivalent, the active drug ingredient in the test formulation must exhibit equivalent rate and extent of absorption to that of the reference product. Pharmacokinetic parameters such as $\mathrm{C}_{\text {max }}$ and AUC are useful tools to evaluate and to compare the systemic exposure of the drug in different products [8]. Some studies describe the pharmacokinetic evaluation of memantine after administration in human volunteers $[6,7,9-11]$ or rats $[12,13]$, and the bioequivalence between oral formulations of memantine tablets [14].

The aim of this study was to evaluate the bioequivalence of two tablet formulations: memantine $10 \mathrm{mg}$ tablets (Clomenac') manufactured by Cobalt Pharmaceuticals, Canada/Arrow Farmacêutica Ltda, relative to reference tablets (Ebix', Lundbeck Inc) after single-dose oral administration in Brazilian healthy volunteers.

\section{Subjects and Methods}

\section{Subjects}

Twenty six adult healthy volunteers of both genders (13 men and

*Corresponding author: Isabela Costa César, Instituto de Ciências Farmacêuticas Alameda Coronel Eugênio Jardim 53, 74175-100, Goiânia, GO, Brazil, Tel: +55 31 34096966; Fax: +55 31 34096976; E-mail: isaccesar@bol.com.br

Received January 20, 2012; Accepted February 18, 2012; Published February 20, 2012

Citation: César IC, Duarte Byrro RM, de Santana e Silva FF, Mundim IM, de Souza Teixeira L, et al. (2012) Bioequivalence Study of Two Oral Formulations of Memantine Tablets in Healthy Brazilian Volunteers after a Single Dose Administration. J Bioequiv Availab 4: 014-017. doi:10.4172/jbb.1000104

Copyright: $\odot 2012$ César IC, et al. This is an open-access article distributed under the terms of the Creative Commons Attribution License, which permits unrestricted use, distribution, and reproduction in any medium, provided the original author and source are credited. 
Citation: César IC, Duarte Byrro RM, de Santana e Silva FF, Mundim IM, de Souza Teixeira L, et al. (2012) Bioequivalence Study of Two Oral Formulations of Memantine Tablets in Healthy Brazilian Volunteers after a Single Dose Administration. J Bioequiv Availab 4: $014-017$. doi:10.4172/jbb.1000104

13 women) who were between the ages of 18 and 50 and within $15 \%$ of their ideal body weight were enrolled in the study. The required sample size was calculated using PASS 2008 software (NCSS, Kaysville, Utah, USA) and considering a minimum of $80 \%$ for power of the test. Subjects were judged eligible for enrolment in this study if they were in compliance with all the inclusion and exclusion criteria described in the protocol.

A physical examination was conducted in each participant. Subject's health was based on findings of a clinical health evaluation, which consisted on ECG and the following laboratory tests: blood glucose, urea, creatinine, AST, ALT, alkaline phosphatase, Gamma GT, total bilirrubin, albumin and total protein, triglycerides, total cholesterol, hemoglobin, hematocrit, total and differential white cell counts, urinalysis and a pregnancy test in women. All subjects were negative for HIV, HBV and HCV.

All subjects were informed with the objectives, drugs, potential risks, dates and activities during the clinical part of the study. A written consent form was signed by each subject. The study protocol was approved by the Ethics Committee of Universidade Estadual de Campinas with the ethical principles described in the Declaration of Helsinki, guidelines for International Conference on HarmonizationGood clinical practices (ICH-GCP).

\section{Drug products}

Two products of memantine $10 \mathrm{mg}$ tablets were studied. The test product was memantine $10 \mathrm{mg}$ tablets (Clomenac, Arrow Farmacêutica Ltda) and the reference was Ebix (Lundbeck Inc) 10 mg tablets.

\section{Study design}

The study was performed to compare the relative bioavailability of two memantine $10 \mathrm{mg}$ tablet formulations under fasting conditions. A single-dose randomized-sequence, open-label, 2-period cross over design was used. A total of 26 subjects of both genders (13 men and 13 women) were admitted to the clinical site on the day before the beginning of the study. Since the evaluated memantine $10 \mathrm{mg}$ tablets are immediate release formulations, a fasting study was performed [8]. Subjects underwent a 10 hour overnight fast and received at 7:00 a.m. either one tablet of Clomenac $10 \mathrm{mg}$ (test product) or Ebix $10 \mathrm{mg}$ (reference product) according to a randomization plan, along with 200 $\mathrm{ml}$ of water. All volunteers were then fasted 4 hours following the drug administration, after which a standard lunch was consumed. No other food was permitted during the "in-house" period. Liquid consumption was permitted ad libitum after lunch but xanthine-containing drinks including tea, coffee and cola were avoided. Systolic and diastolic arterial pressure, heart rate and temperature were recorded just before and hourly after drug administration.

For blood samples collection, a cannula was inserted to each subject's forearm vein and remains there until the 24-hour sample. Blood samples $(8 \mathrm{~mL})$ were collected into EDTA containing tubes before and $0.5,1,2,3,4,5,6,7,8,9,10,11,12,16,24,36,48$ and 72 hours after administration of each memantine tablet. Plasma was obtained by centrifugation and stored into polypropylene tubes at $-70^{\circ} \mathrm{C}$ until analysis by UPLC-MS/MS.

\section{Determination of memantine plasma concentrations}

Chemicals: Memantine reference standard was purchased from Sigma Aldrich Brasil (São Paulo, SP, Brazil) and amantadine (internal standard - IS) reference standard was purchased from the U. S.
Pharmacopeia (Rockville, MD, USA). Ultra-pure water was obtained from a Millipore system (Bedford, MA, USA). Methanol (HPLC grade) was purchased from Tedia (Fairfield, OH, USA) and formic acid, diethyl ether, methylene chloride and sodium hydroxide (analytical grade) were obtained from J.T.Baker (Phillipsburg, NJ, USA).

Sample preparation: A $25 \mu \mathrm{L}$ aliquot of the internal standard solution (200 ng/mL aqueous amantadine) and a $50 \mu \mathrm{L}$ aliquot of 0.05 $\mathrm{M}$ aqueous sodium hydroxide were added to $200 \mu \mathrm{L}$ of plasma sample. The sample was vortex mixed for $10 \mathrm{~s}$. A $1 \mathrm{~mL}$ aliquot of diethyl ether and methylene chloride (7:3) was added and vortex mixed for $5 \mathrm{~min}$. Then, the samples were centrifuged at $13200 \mathrm{rpm}$ for $5 \mathrm{~min}$, at $4^{\circ} \mathrm{C}$. A $0.9 \mathrm{~mL}$ of the organic layer was transferred and evaporated to dryness. The dried extract was reconstituted in $200 \mu \mathrm{L}$ of methanol and vortex mixed for $3 \mathrm{~min}$. A $5 \mu \mathrm{L}$ aliquot was injected into the chromatographic system (UPLC, Acquity system from Waters, Milford, MA, USA).

Chromatographic and mass spectrometric conditions: Memantine concentrations were determined employing an Acquity BEH C ${ }_{18}$ column (50 x $2.1 \mathrm{~mm}$ i.d.; $1.7 \mu \mathrm{m}$ particle size, Waters) and eluted with a mobile phase consisted of water and methanol (40:60) containing $0.05 \%$ formic acid $(\mathrm{v} / \mathrm{v})$, at a flow rate of $0.4 \mathrm{~mL} / \mathrm{min}$. The run time was $2.0 \mathrm{~min}$ and the injection volume was $5 \mu \mathrm{L}$. Mass spectrometric detection was performed using a Quattro Micro triple quadrupole mass spectrometer from Waters (Milford, MA, USA), equipped with an electrospray ion source in positive ionization mode. Nitrogen was used as both the nebulizing and the desolvation gas, and argon was used as the collision gas. The collision energies were optimized at $15 \mathrm{~V}$ for memantine and $18 \mathrm{~V}$ for IS. The Selected Reaction Monitoring (SRM) fragmentation transitions were $\mathrm{m} / \mathrm{z} 180.3 \rightarrow \mathrm{m} / \mathrm{z} 163.1$ and $\mathrm{m} / z 152.0 \rightarrow$ $\mathrm{m} / z 135.2$ for memantine and amantadine, respectively.

Method validation: The validation process was carried out according to Guidance for Industry - Bioanalytical Method Validation, recommended by U.S. Food and Drug Administration [15]. Accordingly the method validation was evaluated in terms of selectivity, linearity, sensitivity, inter and intra-run accuracy and precision, recovery and stability under different conditions.

\section{Pharmacokinetic and statistical analyses}

Individual plasma concentration-time curves were constructed and pharmacokinetics parameters were calculated from plasma levels applying a non-compartmental statistic using Win Non Lin 6.1 software (Pharsight, USA). $\mathrm{C}_{\max }$ was the observed maximum plasma concentration of memantine and $\mathrm{T}_{\max }$ was the sampling time of the maximum plasma concentration. The area under the concentrationtime curve $\left(\mathrm{AUC}_{0-\mathrm{t}}\right)$ from time baseline to the last measurable concentration was obtained by the trapezoidal method. Since the estimated $t_{1 / 2}$ of memantine is around 60 hours, a truncated AUC ${ }_{(0}$. 2h) was obtained, according to the recommendations of FDA Guidance [8]. The total area under the curve $\left(\mathrm{AUC}_{0 \text {-inf }}\right)$ was calculated up to the last measured concentration and the terminal elimination rate constant $(\mathrm{Ke}) . \mathrm{Ke}$ was estimated from the slope of the terminal exponential phase of the memantine curve, by means of linear regression, applied to the semi-log plot of the concentration-time data. The elimination half-life, $t_{1 / 2}$, was then calculated as $\ln (2) / K e$.

Analysis of variance (ANOVA) using log-transformed data was performed at the $5 \%$ significance level to evaluate period, formulation and sequence effects. The $90 \%$ CIs of the geometric means ratios (test/ reference products) of $\mathrm{C}_{\max }, \mathrm{AUC}_{0 \text {-t }}$ and $\mathrm{AUC}_{0 \text {-inf }}$ were determined after $\log$ transformation of the data. Statistical analyses were performed 
Citation: César IC, Duarte Byrro RM, de Santana e Silva FF, Mundim IM, de Souza Teixeira L, et al. (2012) Bioequivalence Study of Two Oral Formulations of Memantine Tablets in Healthy Brazilian Volunteers after a Single Dose Administration. J Bioequiv Availab 4: 014-017. doi:10.4172/jbb.1000104

using Bioequivalence Wizard of Win Non Lin 6.1 software (Pharsight, USA). Bioequivalence was considered when the ratio of averages of $\mathrm{AUC}_{0+\mathrm{t}}$ and $\mathrm{C}_{\mathrm{max}}$ fell within a predetermined range of $80-125 \%$.

\section{Results}

\section{Method validation}

Selectivity study showed that there are no significant interferences from endogenous compounds of plasma at the retention time of neither memantine nor IS. The calibration curve showed good linearity over the range of $0.1-50 \mathrm{ng} / \mathrm{mL}$, with correlation coefficient higher than 0.99 and a weighted factor $1 / x^{2}$. Under the described conditions, the obtained LLOQ was $0.1 \mathrm{ng} / \mathrm{mL}$.

Intra-run precision $(n=5)$ of the method ranged from 4.4 to $7.8 \%$, while accuracy values were from 92.7 to $107.0 \%$. Inter-run precision $(n=15)$ ranged from 0.2 to $2.9 \%$ and inter-day accuracy were from 94.2 to $107.1 \%$. According to these results the assay is accurate and precise for memantine in the studied concentration range.

The mean recovery rate of memantine $(n=15)$, determined at three concentrations, was $54.4 \%$. The mean recovery of the IS was shown to be $61.6 \%(n=15)$.

In the stability study, memantine proved to be stable in plasma samples for at least $6 \mathrm{~h}$ at room temperature and for 60 days at $-70^{\circ} \mathrm{C}$. In the post-preparative stability study, memantine was stable for $10 \mathrm{~h}$ after sample preparation, at $20^{\circ} \mathrm{C}$, and after three complete freeze/thaw cycles on consecutive days. In addition, memantine and IS were found to be stable in working solutions for at least 5 days at $5^{\circ} \mathrm{C}$ and for $6 \mathrm{~h}$ at room temperature, as the mean changes in analyte content were within $\pm 15 \%$ of initial concentration.

\section{Tolerability analysis}

Memantine was well tolerated at the administered dose. All biochemical parameters did not have any clinical relevant alterations. No serious adverse effects were either reported or observed.

\section{Pharmacokinetic and statistical analysis}

Two subjects drop out the period 2 for personal reasons, so that a total of 24 volunteers completed the clinical stage of the study. The mean plasma concentration-time curves of memantine obtained for the reference $(\mathrm{R})$ and test $(\mathrm{T})$ formulations are shown in Figure 2. The main pharmacokinetic parameters for both formulations were calculated (Table 1). On ANOVA of $\mathrm{C}_{\max }$ and $\mathrm{AUC}_{(0-\mathrm{t})}$ (using logtransformed data), no significant period, formulation or sequence effects were detected (Table 2).

Table 3 presents the ratios and the respective confidence intervals for bioequivalence analysis. All $90 \%$ CIs of the geometric mean ratios of $\mathrm{C}_{\max }$ and $\mathrm{AUC}_{(0-\mathrm{t})}$ fell within the predetermined range of $80 \%$ to $125 \%$.These results suggested that the bioequivalence criteria were met.

\section{Discussion}

Pharmacokinetic and bioequivalence studies require sensitive and selective methods for the quantitation of drugs and active metabolites in biological matrices without interference of endogenous compounds [16]. Quantitation of memantine in biological matrices represents a challenge in the bioanalytical field, since the molecule does not possess chromophores, so that it is undetectable in the ultravioletvisible range. In order to make possible the quantitation of memantine using fluorescence detection, pre-column derivatization procedures

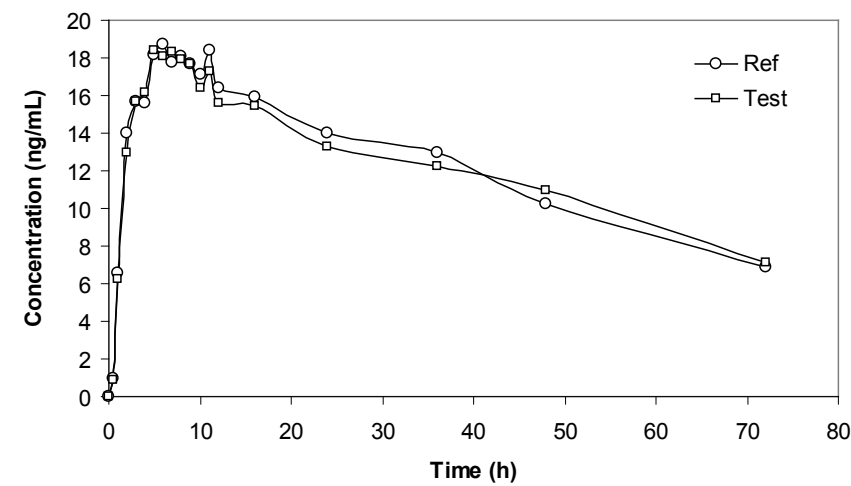

Figure 2: Plasma concentration - time curves of memantine after the oral administration of $10 \mathrm{mg}$ tablets of reference and test formulations in 24 healthy volunteers.

\begin{tabular}{|c|c|c|}
\hline Pharmacokinetic parameters & Reference & Test \\
\hline $\mathrm{C}_{\max }(\mathrm{ng} / \mathrm{mL})$ & $21.6 \pm 5.1$ & $21.8 \pm 6.0$ \\
\hline $\mathrm{T}_{\max }(\mathrm{h})$ & $7.8 \pm 3.2$ & $6.4 \pm 2.2$ \\
\hline $\mathrm{AUC}_{0-\mathrm{t}}(\mathrm{ng} \cdot \mathrm{h} / \mathrm{mL})$ & $875.6 \pm 167.3$ & $865.6 \pm 176.3$ \\
\hline $\mathrm{AUC}_{0 \text {-inf }}(\mathrm{ng} \cdot \mathrm{h} / \mathrm{mL})$ & $1313.2 \pm 274.4$ & $1422.4 \pm 388.5$ \\
\hline$t_{1 / 2}(\mathrm{~h})$ & $42.7 \pm 12.1$ & $52.2 \pm 19.8$ \\
\hline
\end{tabular}

Table 1: Pharmacokinetic parameters (mean \pm standard deviation) of memantine after the oral administration of single dose of reference and test formulations ( $n$ $=24$ ).

\begin{tabular}{|c|c|c|}
\hline & \multicolumn{2}{|c|}{ P-values obtained for the effects of ANOVA test (Sequential) } \\
\hline & $\mathrm{C}_{\max }$ & AUC $_{0-\mathrm{t}}$ \\
\hline Sequence & 0.1382 & 0.2781 \\
\hline Formulation & 0.4470 & 0.5353 \\
\hline Period & 0.6021 & 0.3105 \\
\hline & P-values obtained for the effects of ANOVA test (Partial) & AUC $_{0-\mathrm{t}}$ \\
\hline Sequence & $\mathrm{C}_{\max }$ & 0.2781 \\
\hline Formulation & 0.1382 & 0.6063 \\
\hline Period & 0.4805 & 0.3105 \\
\hline
\end{tabular}

Table 2: P-values obtained for the effects of ANOVA test.

involving the reaction of memantine with fluorescent compounds have been developed [10-13]. However, these methods are complex and time-consuming, besides present poor specificity, since other sample components could also be derivatized. In the last years, liquid chromatography coupled to mass spectrometric detection has almost completely replaced ultraviolet, electrochemical or fluorescence detection in the bioanalytical field, due to its unmatched sensitivity and extraordinary selectivity [17]. In the present work, we developed a rapid and high selectivity method, using ultra performance liquid chromatography coupled to tandem mass spectrometry, which allowed the direct quantitation of memantine in human plasma.

Chromatographic conditions were optimized to achieve good resolution and to increase the signal of analytes, as well as to minimize run times. Different mobile phases were evaluated and water and methanol (40:60) containing $0.05 \%$ formic acid ( $\mathrm{v} / \mathrm{v})$ provided the most efficient chromatography. The use of smaller particles of stationary phase allows UPLC to increase the speed of analysis and 
Citation: César IC, Duarte Byrro RM, de Santana e Silva FF, Mundim IM, de Souza Teixeira L, et al. (2012) Bioequivalence Study of Two Oral Formulations of Memantine Tablets in Healthy Brazilian Volunteers after a Single Dose Administration. J Bioequiv Availab 4: $014-017$. doi:10.4172/jbb.1000104

\begin{tabular}{|l|c|c|}
\hline \multicolumn{1}{|c|}{ Parameters } & $\mathrm{C}_{\max }$ & $\mathrm{AUC}_{\text {0-t }}$ \\
\hline Ratio T/R (\%) & 100.1 & 98.8 \\
\hline Lower limit (\%) & 92.9 & 93.9 \\
\hline Upper limit (\%) & 107.9 & 103.9 \\
\hline Within-subject coefficient of variation (\%) & 11.59 & 5.53 \\
\hline Between-subjects coefficient of variation (\%) & 26.61 & 20.88 \\
\hline
\end{tabular}

Table 3: Statistical results of memantine pharmacokinetic parameters.

the chromatographic performance. The developed method offers the advantage over those previously reported using LC-MS/MS [14] showing a faster chromatographic total run time. Since a high number of samples are needed for pharmacokinetics and bioequivalence studies, the very fast UPLC separation combined with a low LLOQ $(0.1$ $\mathrm{ng} / \mathrm{mL}$ ) described in this work allows the application of the method for high throughput analysis.

In this study two formulations of memantine had been evaluated. Washout period was adequate, since there were no quantifiable concentrations of memantine before drug administration in the second period of the study, indicating that there was no carryover effect from the first to second period. The results of this bioequivalence study showed the equivalence of the two studied products in terms of the rate of absorption as indicated by $\mathrm{C}_{\max }$ and in terms of the extent of absorption as indicated by AUC $\mathrm{AO-t)}_{(\mathrm{t})}$. The mean plasma curves of both products are almost superimposable suggesting that not only $\mathrm{C}_{\max }$ and $\mathrm{AUC}_{(0-\mathrm{t})}$ but also the time course of plasma levels over the whole sampling period are identical.

\section{Conclusion}

In this study in healthy, fasting, Brazilian, adult subjects, single doses of oral tablets of memantine $10 \mathrm{mg}$ met the regulatory requirements to assume bioequivalence based on the rate and extent of absorption. Thus, the tested $10 \mathrm{mg}$ memantine tablets (Clomenac, Arrow Farmacêutica Ltda) can be considered interchangeable in medical practice to reference formulation (Ebix, Lundbeck Inc).

\section{References}

1. Osborn GG, Saunders AV (2010) Current treatments for patients with Alzheimer disease. J Am Osteopath Assoc 110: S16-26.

2. Wu TY, Chen CP, Jinn TR (2010) Alzheimer's disease: aging, insomnia and epigenetics. Taiwan J Obstet Gynecol 49: 468-472.

3. Wollen KA (2010) Alzheimer's disease: the pros and cons of pharmaceutical, nutritional, botanical, and stimulatory therapies, with a discussion of treatment strategies from the perspective of patients and practitioners. Altern Med Rev 15: $223-244$

4. Grossberg GT, Pejovic V, Miller ML, Graham SM (2009) Memantine therapy of behavioral symptoms in community-dwelling patients with moderate to severe Alzheimer's disease. Dement Geriatr Cogn Disord 27: 164-172.

5. Thomas SJ, Grossberg GT (2009) Memantine: a review of studies into its safety and efficacy in treating Alzheimer's disease and other dementias. Clin Interv Aging 4: 367-377.

6. Periclou A, Ventura D, Rao N, Abramowitz W (2006) Pharmacokinetic study of memantine in healthy and renally impaired subjects. Clin Pharmacol Ther 79: $134-143$

7. Liu MY, Meng SN, Wu HZ, Wang S, Wei MJ (2008) Pharmacokinetics of single-dose and multiple-dose memantine in healthy Chinese volunteers using an analytic method of liquid chromatography-tandem mass spectrometry. Clin Ther 30: 641-653.

8. Rockville MD (2003) Food and Drug Administration. Guidance for Industry:

Bioavailability and Bioequivalence Studies for Orally Administered Drug Products - General Considerations

9. Leis HJ, Fauler G, Windischhofer W (2002) Quantitative analysis of memantine in human plasma by gas chromatography/negative ion chemical ionization/ mass spectrometry. J Mass Spectrom 37: 477-480.

10. Zarghi A, Shafaati A, Foroutan SM, Khoddam A, Madadian B (2010) Sensitive and rapid HPLC method for determination of memantine in human plasma using OPA derivatization and fluorescence detection: application to pharmacokinetic studies. Sci Pharm 78: 847-856.

11. Toker SE, Sağırlı O, Çetin SM, Önal A (2011) A new HPLC method with fluorescence detection for the determination of memantine in human plasma. $J$ Sep Sci 34: 2645-2649.

12. Hassan MG, Emara KM, Mohamed HA, Abdel-Wadood HM, Ikeda R, et al. (2011) Determination of memantine in rat plasma by HPLC-fluorescence method and its application to study of the pharmacokinetic interaction between memantine and methazolamide. Biomed Chromatogr 26: 214-219.

13. Xie MF, Zhou W, Tong XY, Chen YL, Cai $Y$, et al. (2011) High-performance liquid chromatographic determination of memantine hydrochloride in rat plasma using sensitive fluorometric derivatization. J Sep Sci 34: 241-246.

14. Almeida AA, Campos DR, Bernasconi G, Calafatti S, Barros FA, et al. (2007) Determination of memantine in human plasma by liquid chromatography electrospray tandem mass spectrometry: application to a bioequivalence study J Chromatogr B Analyt Technol Biomed Life Sci 848: 311-316.

15. Rockville MD (2001) Food and Drug Administration. Guidance for Industry: Bioanalytical Method Validation.

16. Zhou S, Song Q, Tang Y, Naidong W (2005) Critical review of development validation and transfer for high throughput bioanalytical LC-MS/MS methods. Current Pharmaceutical Analysis 1: 3-14.

17. Hopfgartner G, Bourgogne E (2003) Quantitative high throughput analysis of drugs in biological matrices by mass spectrometry. Mass Spectrom Rev 22 : 195-214. 